\title{
RETRACTED ARTICLE: Thermal, mechanical, and tribological properties of sodium-montmorillonite-nanoparticle-reinforced polyethersulfone and polytetrafluoroethylene ternary composites
}

\author{
Shicheng YAN ${ }^{1,2,3}$, Yahong XUE ${ }^{1,2,3, *}$, Yahui HU ${ }^{1,2,3}$, Shoujun WANG ${ }^{1,2,3}$ \\ ${ }^{1}$ Tianjin Key Laboratory for Advanced Mechatronic System Design and Intelligent Control, School of Mechanical Engineering, Tianjin \\ University of Technology, Tianjin 300384, China \\ ${ }^{2}$ National Demonstration Center for Experimental Mechanical and Electrical Engineering Education, Tianjin University of Technology, \\ Tianjin 300384, China \\ ${ }^{3}$ College of Mechanical Engineering, Tianjin University of Technology, Tianjin 300384, China \\ Received: 09 September 2019 / Revised: 05 November 2019/Accepted: 15 November 2019 \\ (C) The author(s) 2019.
}

The Editor-in-Chief has retracted this article [1] because a large number of figures as well significant parts of the text overlap with the 2017 Ph.D. thesis by Zhen Zuo [2]. All authors agree to this retraction.

[1] Yan S C, Xue Y H, Hu Y H, Wang S J. Thermal, mechanical, and tribological properties of sodium-montmorillonite-nanoparticlereinforced polyethersulfone and polytetrafluoroethylene ternary composites. Friction (2020). https://doi.org/10.1007/s40544-019-0343-x.

[2] Zuo Z. Research on tribological property and friction interface interaction of PES/PTFE composite. Ph.D Thesis. Qinhuangdao (China): Yanshan University, 2017. 